\title{
Pilose antler polypeptide protects against sevoflurane-mediated neurocyte injury
}

\author{
SHUPING LI ${ }^{1}$ and JIAXUAN HE ${ }^{2}$ \\ ${ }^{1}$ Anesthesiology Department, Xinjiang Uygur Autonomous Region Hospital of TCM, Urumchi, Xinjiang 830000; \\ ${ }^{2}$ Anesthesiology Department, The Second Affiliated Hospital of Xi'an Jiaotong University, Xi'an, Shaanxi 710004, P.R. China
}

Received January 18, 2018; Accepted August 31, 2018

DOI: $10.3892 / \mathrm{mmr} .2018 .9582$

\begin{abstract}
Pilose antler polypeptide (PAP) is an active substance isolated from the traditional Chinese medicine pilose antler, which possesses multiple biological activities. In the present study, the role and mechanism of PAP in sevoflurane (SEV)-induced neurocyte injury was explored. Cell viability was determined by Cell Counting kit- 8 assay. Cell proliferation and apoptosis were analyzed by flow cytometry. Western blotting and reverse transcription-quantitative polymerase chain reaction analysis were used to evaluate the protein and mRNA expression levels, respectively. The results revealed that PAP enhanced the cell viability of SEV-treated nerve cells. In addition, through modulation of apoptosis-associated protein expression, PAP suppressed SEV-induced nerve cell apoptosis. Furthermore, PAP activated the p38 mitogen-activated protein kinase (p38)/c-Jun N-terminal kinase (JNK) pathway in the neurocyte injury model, whereas inhibition of the p38/JNK pathway reversed the beneficial effects produced by PAP. In conclusion, PAP protected against SEV-mediated neurocyte injury via upregulation of the $\mathrm{p} 38 / \mathrm{JNK}$ pathway. The present findings suggested that PAP may be an effective agent for neurocyte injury.
\end{abstract}

\section{Introduction}

Numerous infants and young children receive surgical treatments and anesthesia (1). Between the embryonic period and the second year following birth, the human brain is growing and developing. In particular, the rapid growth of cerebral neurons, and the formation of axons, dendrites and synapses, may be observed during this period (2). Nerve cells are sensitive to a number of general anesthetic drugs; therefore, exposing the

Correspondence to: Dr Jiaxuan He, Anesthesiology Department, The Second Affiliated Hospital of Xi'an Jiaotong University, 157 Xiwu Road, Xi'an, Shaanxi 710004, P.R. China

E-mail: jiaxuan_HeJXH@163.com

Key words: pilose antler polypeptide, p38 mitogen-activated protein kinase, c-Jun $\mathrm{N}$-terminal kinase, neurocytes, sevoflurane, Bcl-2-associated $\mathrm{X}$ protein, caspase- 3 developing central nervous system to these general anesthetics may cause brain damage (3). Sevoflurane (SEV) serves as a commonly used general anesthetic drug that has been widely adopted for infant anesthesia (4). Long-term exposure to SEV may cause neurological disorders and may lead to neurodegeneration in the developing brain (5). Additionally, SEV may impair memory and cognitive functions in infants and young children (3). Studies have demonstrated that in rats and mice, exposure to clinically relevant anesthetics, including isoflurane and SEV, results in neurological disorders (6-8), synaptic alterations in the hippocampus $(9,10)$, a reduction in axonal connections (11) and cerebral cortex axon disorders $(12,13)$. These findings indicated that exposure to anesthesia may cause damage to the developing brain.

Mitogen-activated protein kinases (MAPKs) are a type of protein kinase with dual serine and threonine phosphorylation capacity, which act as a signal transduction system that mediates extracellular signals (14). p38 MAPK (p38) and c-Jun N-terminal kinase (JNK) represent crucial members of the MAPK family. Studies have demonstrated that p38 serves important roles during anti-inflammatory processes $(15,16)$, whereas the JNK pathway is considered to be critical for embryonic morphogenesis, cell differentiation and the regulation of apoptosis $(17,18)$. However, the modulation of the p38/JNK pathway by pilose antler polypeptide (PAP) remains to be elucidated.

Pilose antler (PA) is obtained from male Cervus nippon Temminck or Cervus elaphus (19) and used to isolate PAP. Studies have demonstrated that PAP possesses multiple biological activities, including ossification (20), anti-inflammation (21) and anti-oxidative stress (22). Furthermore, it has been revealed that PA contains insulin-like growth factors and the associated receptors, which may promote protein synthesis in nerve cells and accelerate the growth of axons (23). However, the role of PAP in protecting nerve cells during SEV-induced injury remains unclear.

In the present study, the role of PAP and the p38/JNK pathway in SEV-induced neurocyte injury was investigated.

\section{Materials and methods}

Reagents. PAP was obtained from Affiliated hospital of Changchun University of Chinese medicine (Jilin, China). SEV-mixed gas $(3 \%)$ was purchased from Xilong Scientific Co., Ltd. (Shenzhen, China). 
Cell culture. Sprague Dawley rats (8-12 weeks; 3 males, 7 females; weight, 220-360 g) were obtained from Guangdong Medical Laboratory Animal Center (Foshan, China). The animals were kept at $21 \pm 2{ }^{\circ} \mathrm{C}$ with humidity of $60-70 \%$ and a 12-h light/dark cycle, and had free access to food and water. The animals were mated to produce neonatal rats. A total of five 24 h-old neonatal rats were used to isolate neuronal cells. Neonatal rats were sacrificed by rapid cervical dislocation. Subsequently, the animals were disinfected with $75 \%$ ethanol and transferred to Hank's balanced salt solution. The hippocampus was removed and digested with $0.125 \%$ trypsin (Beyotime Institute of Biotechnology, Haimen, China) in a cell incubator for $10 \mathrm{~min}$ at $37^{\circ} \mathrm{C}$ with $5 \% \mathrm{CO}_{2}$. The supernatant was discarded. Subsequently, Dulbecco's modified Eagle's medium (Gibco; Thermo Fisher Scientific, Inc., Waltham, MA, USA) supplemented with $10 \%$ fetal bovine serum (Gibco; Thermo Fisher Scientific, Inc.) was added to the tissues and gently agitated at room temperature for 3-4 min. The obtained nerve cells were incubated at $37^{\circ} \mathrm{C}$ with $5 \% \mathrm{CO}_{2}$. The cells were observed under a light microscope (magnification, $x 200$ ). After 7 days of culture in Neurobasal medium (Thermo Fisher Scientific, Inc.), nerve cells were treated with SEV. Neurobasal medium was replaced prior to the treatment with SEV. The protocols for the animal experiments were approved by the Ethics Committee of Xinjiang Uygur Autonomous Region Hospital of TCM (Urumchi, China).

Experimental groups. The five treatment groups in the present study were as follows: Control group (nerve cells with no treatment), SEV group (nerve cells treated with $3 \%$ SEV mixed gas for $12 \mathrm{~h}$ in an anesthesia box) and PAP+SEV groups (nerve cells pretreated with 10, 20 or $30 \mu \mathrm{M}$ PAP for $6 \mathrm{~h}$, and subsequently treated with $3 \%$ SEV mixed gas for $12 \mathrm{~h}$ in an anesthesia box). The dosage of PAP was set according to two previous studies $(24,25)$. SB203580 $(10 \mu \mathrm{M}$; Selleck Chemicals, Houston, TX, USA) was used to inhibit p38. SB203580 was added 45 min before the PAP treatment.

Cell viability analysis. A Cell Counting kit-8 assay (CCK-8; Beyotime Institute of Biotechnology) was performed to assess the cell viability of nerve cells. Cultured nerve cells in the logarithmic phase $\left(\sim 6 \times 10^{4}\right.$ cells $\left./ \mathrm{ml}\right)$ were seeded into 96-well plates, and maintained at $37^{\circ} \mathrm{C}$ with $5 \% \mathrm{CO}_{2}$ for $12 \mathrm{~h}$. Subsequently, $10 \mu \mathrm{l}$ CCK-8 reagent was added to the wells after 12, 24 and $48 \mathrm{~h}$. Nerve cells were maintained for another $3 \mathrm{~h}$, and a microplate reader (Bio-Rad Laboratories, Inc., Hercules, CA, USA) was used to record the absorbance at $450 \mathrm{~nm}$. Cell viability was evaluated as the proportion of cell survival compared with the control.

Flow cytometry (FCM). FCM was performed to test the proliferation and apoptosis of nerve cells. Cultured nerve cells were treated with $0.25 \%$ trypsin (Beyotime Institute of Biotechnology). The supernatant was removed and the nerve cells at a density of $1 \times 10^{6}$ cells $/ \mathrm{ml}$ were resuspended in PBS. The proliferation was detected using CFSE (Invitrogen; Thermo Fisher Scientific, Inc.). The cells were stained with CFSE for $10 \mathrm{~min}$ at $37^{\circ} \mathrm{C}$. Nerve cells were incubated with Annexin V-phycoerythrin (PE) and 7-ADD (Annexin V-PE Apoptosis Detection kit, BD Pharmingen; BD Biosciences, Franklin Lakes, NJ, USA) in the dark at room temperature for
15 min. Cells were acquired on a FACSCalibur flow cytometer (BD Biosciences, Franklin Lakes, NJ, USA) and BD CellQuest software version 5.1 (BD Biosciences) was used for data analysis.

Western blot analysis. Proteins were isolated using NP-40 lysis buffer (Beyotime Institute of Biotechnology). The concentration of proteins was detected using a Bicinchoninic Acid Assay kit (Pierce; Thermo Fisher Scientific, Inc.). Proteins $(25 \mu \mathrm{g} /$ lane) were separated by SDS-PAGE on a $12 \%$ gel. The separated products were transferred onto a polyvinylidene fluoride membrane (EMD Millipore, Billerica, MA, USA). The membrane was blocked with $5 \%$ non-fat milk at room temperature for $2 \mathrm{~h}$. Blotting was performed with specific primary antibodies at $4^{\circ} \mathrm{C}$ overnight: Anti-activated-caspase-3 (1:500; cat. no. ab13847; rabbit anti-rat), anti-pro-caspase-3 (1:10,000; cat. no. ab32499; rabbit anti-rat), anti-Bcl-2-associated $\mathrm{X}$ protein (Bax; 1:1,000; cat. no. ab32503; rabbit anti-rat), anti-B-cell lymphoma 2 (Bcl-2; 1:1,000; cat. no. ab59348; rabbit anti-rat), anti-phosphorylated (p)-p38 (1:1,000; cat. no. ab4822; rabbit anti-rat), anti-p38 (1:1,000; cat. no. ab170099; rabbit anti-rat), anti-p-JNK (1:1,000; cat. no. ab124956; rabbit anti-rat), anti-JNK (1:1,000; cat. no. ab179461; rabbit anti-rat) and anti-GAPDH (1:2,500; cat. no. ab9485; rabbit polyclonal; all Abcam, Cambridge, UK). The membrane was washed with PBST buffer (Beijing Solarbio Science \& Technology Co., Ltd., Beijing, China) for 3 times ( $5 \mathrm{~min} /$ time). Horseradish peroxidase-conjugated secondary antibodies (1:5,000; cat. no. ab205718; goat anti-rabbit; Abcam) were added and incubated at room temperature for $1 \mathrm{~h}$. Enhanced chemiluminescent reagents (Millipore, Billerica, MA, USA) in combination with an ECL system (Amersham Pharmacia, Piscataway, NJ, USA) were used to visualize the protein bands. The density of the blots was read by Quantity One software version 4.6.9 (Bio-Rad Laboratories, Inc.).

Reverse transcription-quantitative polymerase chain reaction (RT-qPCR) analysis. Total RNA was extracted from cultured nerve cells using TRIzol ${ }^{\circledR}$ reagent (Beyotime Institute of Biotechnology). RNA was reverse transcribed to cDNA using BeyoRT II First Strand cDNA Synthesis kit (Beyotime Institute of Biotechnology) according to the manufacturer's protocols. SYBR-Green PCR Master Mix (Thermo Fisher Scientific, Inc.) was performed using an Applied Biosystems ${ }^{\circledR} 7500$ thermocycler (Applied Biosystems; Thermo Fisher Scientific, Inc.). The PCR cycling conditions were as follows: Pretreatment at $94^{\circ} \mathrm{C}$ for $4 \mathrm{~min}$, followed by 35 cycles of $95^{\circ} \mathrm{C}$ for $15 \mathrm{sec}$ and $68^{\circ} \mathrm{C}$ for $30 \mathrm{sec}$, a final extension at $75^{\circ} \mathrm{C}$ for $10 \mathrm{~min}$ and hold at $4^{\circ} \mathrm{C}$. The following primers were designed by Invitrogen (Thermo Fisher Scientific, Inc.): caspase-3 forward, 5'-TGTCGATGC AGCTAACCTCA-3' and reverse, 5'-GCAGTAGTCGCCTCT GAAGA-3' (241 bp); Bax forward, 5'-GAGACACCTGAG CTGACCTT-3' and reverse, 5'-CGTCTGCAAACATGT CAGCT-3' (187 bp); Bcl-2 forward, 5'-AACTCTTCAGGG ATGGGGTG-3' and reverse, 5'-GCTGGGGCCATATAG TTCCA-3' (209 bp); and GAPDH forward, 5'-AGTCTACTG GCGTCTTCACC-3' and reverse, 5'-CCACGATGCCAA AGTTGTCA-3' (225 bp). GAPDH was used as the internal 
A

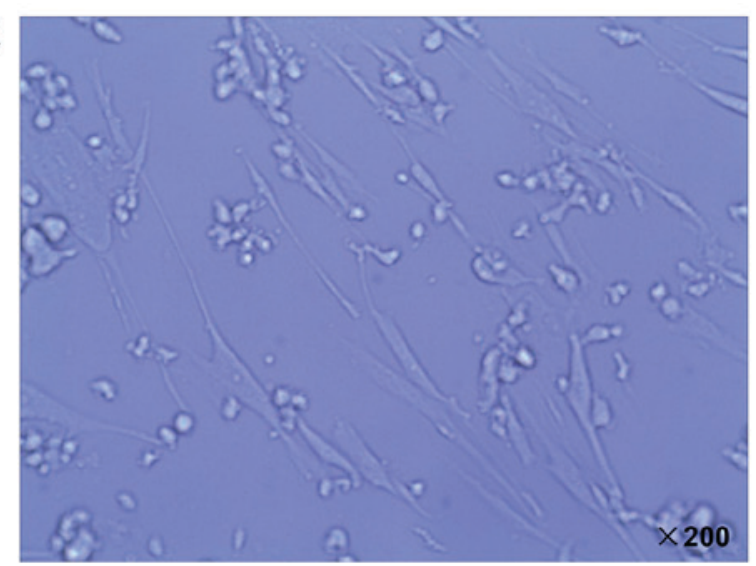

B

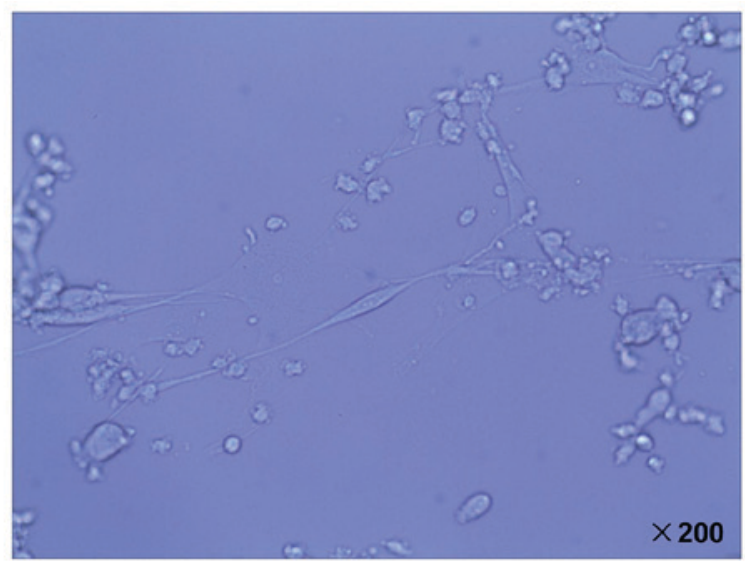

Figure 1. Identification of rat neurocytes. Primary rat hippocampal neurocytes cultured for (A) 2 days and (B) 6 days were observed under an inverted fluorescence microscope (magnification, x200).
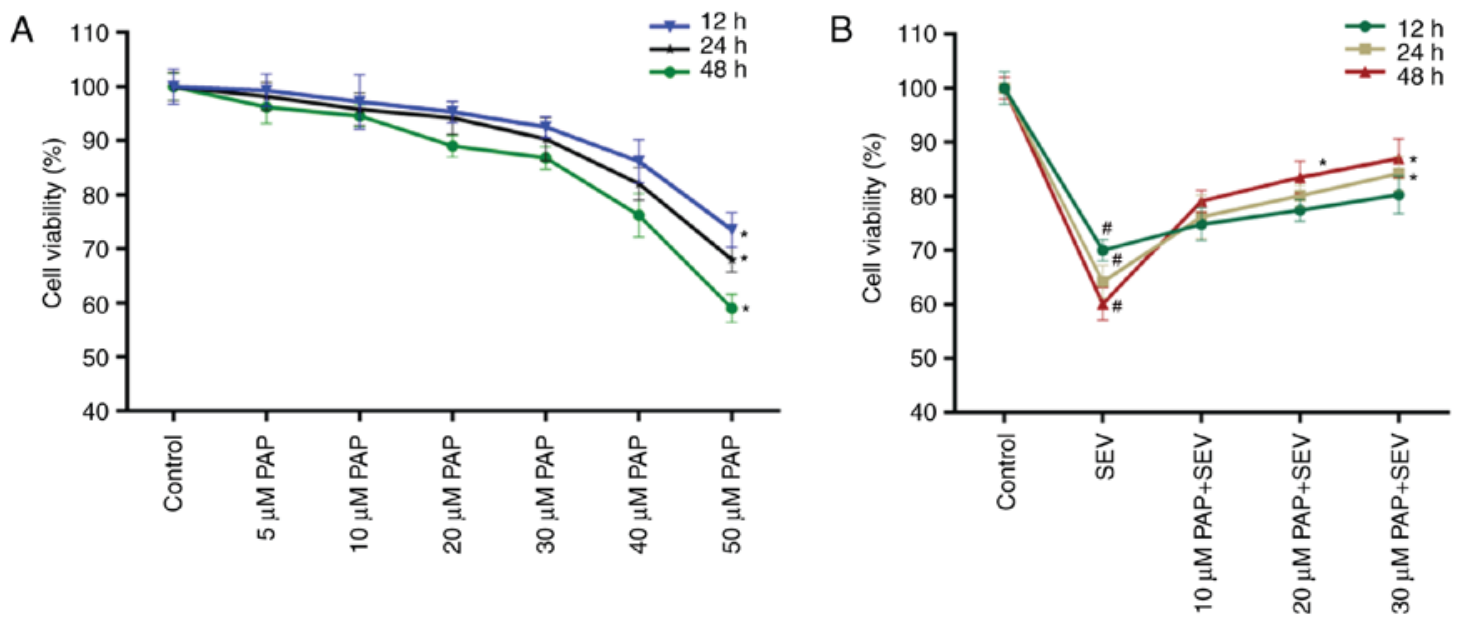

Figure 2. PAP enhances the cell viability of SEV-treated nerve cells. (A) A CCK-8 assay was performed to determine the cell viability of nerve cells treated with different concentrations of PAP $(5,10,20,30,40$ and $50 \mu \mathrm{M})$. ${ }^{*} \mathrm{P}<0.05$ vs. respective control. (B) CCK- 8 assay was performed in nerve cells pretreated with different concentrations of PAP $(10,20$ and $30 \mu \mathrm{M})$ and subjected to SEV. ${ }^{\#} \mathrm{P}<0.05$ vs. Control, ${ }^{*} \mathrm{P}<0.05$ vs. respective SEV group. PAP, pilose antler polypeptide; SEV, sevoflurane.

control. The relative gene expression levels were calculated using the $2^{-\Delta \Delta \mathrm{Cq}}$ method (26).

Statistical analysis. The results are presented as the mean \pm standard deviation for at least three independent experiments. The experimental data were analyzed by one-way analysis of variance followed by Tukey's post hoc test. $\mathrm{P}<0.05$ was considered to indicate a statistically significant difference. GraphPad Prism version 6.0 (GraphPad Software, Inc., La Jolla, CA, USA) was used to analyze the data.

\section{Results}

Identification of primary rat hippocampal neurons. Neurons were isolated from rat hippocampus and cultured for $>2$ days before they were visualized under a microscope. Neuron cells with flat polygonal shape were observed (Fig. 1A) and a visible halo was identified around the nerve cells (Fig. 1B). These nerve cells were harvested and prepared for subsequent experiments.
PAP enhances the cell viability of SEV-treated nerve cells. The cell viability of nerve cells treated with different concentrations of PAP for 12, 24 and $48 \mathrm{~h}$ was determined. A decrease in nerve cell viability was observed when the PAP concentration was $>40 \mu \mathrm{M}$ (Fig. 2A); therefore, nerve cells were treated with 10, 20 and $30 \mu \mathrm{M}$ PAP for all subsequent experiments. The CCK-8 data also demonstrated that compared with the control, SEV decreased the cell viability of nerve cells; however, in the presence of PAP, the cell viability of SEV-treated nerve cells was markedly rescued in a dose-dependent manner (Fig. 2B).

PAP increases cell proliferation of SEV-treated nerve cells. The proliferation of nerve cells treated with SEV and different concentrations of PAP was evaluated. The FCM data revealed that treatment with SEV significantly reduced the number of nerve cells in the M1 phase. However, in the groups that were pretreated with PAP, the number of nerve cells in M1 phase was significantly increased (Fig. 3; $\mathrm{P}<0.05$ ). These data suggested that SEV reduced the proliferation capacity of nerve cells, while PAP promoted cell proliferation in SEV-treated nerve cells. 

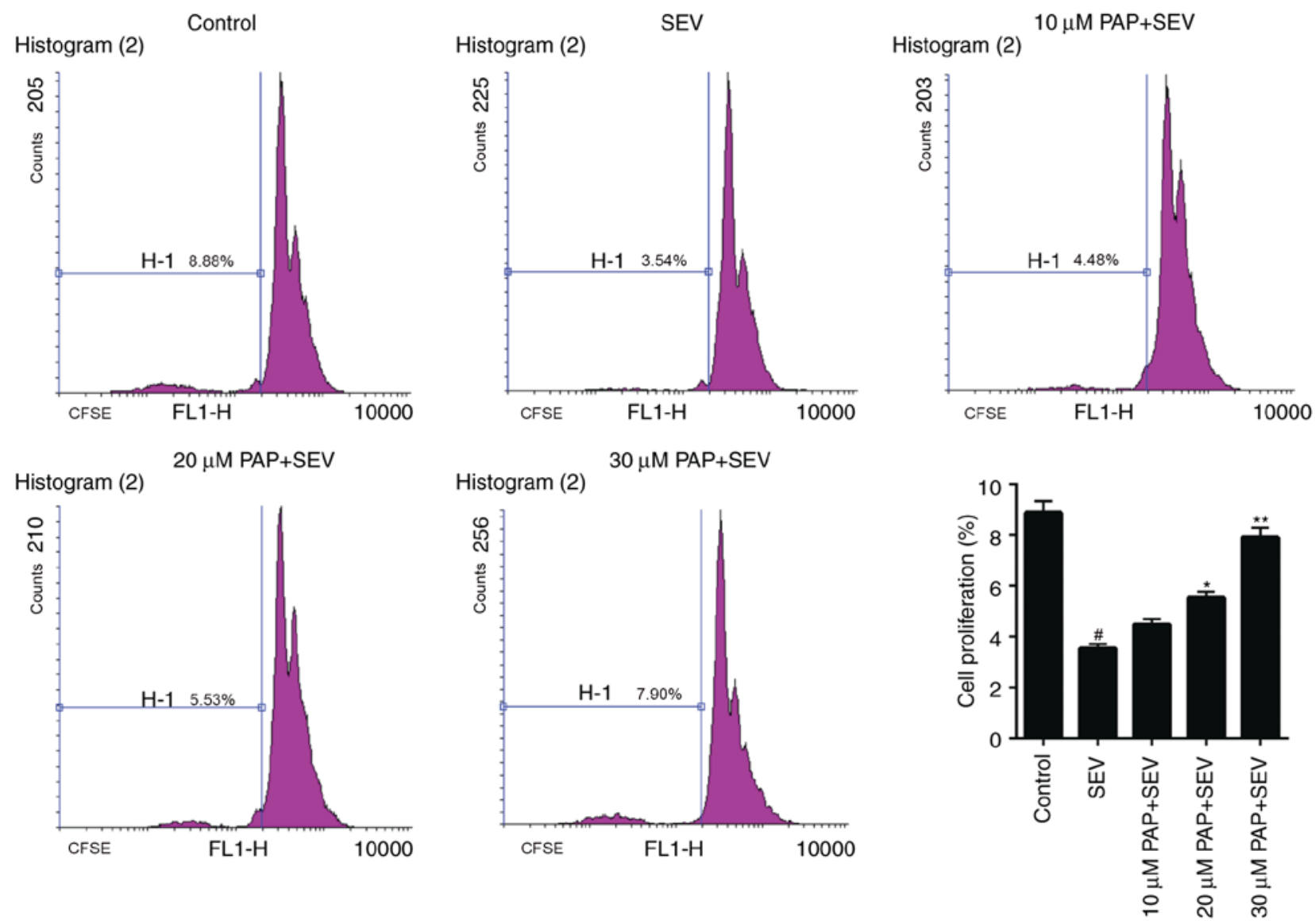

Figure 3. PAP increases the cell proliferation of SEV-treated nerve cells. Flow cytometry was used to analyze proliferation of nerve cells treated with SEV alone, or pretreated with different concentrations of PAP $(10,20$ and $30 \mu \mathrm{M})$ and subjected to SEV. ${ }^{\prime \prime} \mathrm{P}<0.05$ vs. Control, ${ }^{*} \mathrm{P}<0.05,{ }^{* * *} \mathrm{P}<0.01 \mathrm{vs}$. SEV. H-1, M1 phase; PAP, pilose antler polypeptide; SEV, sevoflurane.

PAP suppresses the apoptosis of SEV-treated nerve cells. The apoptosis of nerve cells treated with SEV and different concentrations of PAP was evaluated. The FCM data revealed that the proportion of apoptotic nerve cells in the SEV group was $26.37 \%$, which was markedly higher compared with that in the control group (4.18\%). However, in the groups pretreated with 20 and $30 \mu \mathrm{M}$ PAP, the apoptosis rates of the nerve cells were decreased from $26.37 \%$ to 20.93 and $15.99 \%$, respectively (Fig. 4; $\mathrm{P}<0.05$ ). According to the FCM results, the apoptosis of nerve cells was markedly lower in the PAP groups compared with the SEV group.

PAP modulates expression of apoptosis-associated proteins. Based on the results of PAP-induced suppression of apoptosis in SEV-treated nerve cells, the mechanisms were further investigated in the present study. The expression levels of apoptosis-associated proteins in nerve cells, including caspase-3, Bax and Bcl-2, were determined. The RT-qPCR data demonstrated that the expression levels of caspase-3 and Bax in nerve cells treated with SEV were significantly upregulated. However, in the groups pretreated with different concentrations of PAP, significant decreases in the expression levels of caspase- 3 and Bax were observed. In addition, the results revealed that treatment with SEV markedly reduced the Bcl-2 expression levels in nerve cells, while treatment with PAP significantly upregulated $\mathrm{Bcl}-2$ expression levels in SEV-treated nerve cells (Fig. 5A; $\mathrm{P}<0.05$ ). The western blot data displayed similar trends for activated-caspase-3, Bax and $\mathrm{Bcl}-2$ protein expression in nerve cells from the different treatment groups. Additionally, it was demonstrated that treatment with SEV significantly downregulated the protein expression levels of pro-caspase-3 in nerve cells, while pretreatment with PAP significantly enhanced pro-caspase-3 expression in SEV-induced nerve cells and decreased the activated-caspase-3 expression in SEV-induced nerve cells (Fig. 5B; P $<0.05$ ). These results revealed that PAP suppressed the apoptosis of SEV-treated nerve cells by modulating the expression levels of caspase-3, Bax and Bcl-2.

PAP activates the p38/JNK pathway. The western blot results demonstrated that the expression levels of p-p38 and p-JNK were markedly downregulated by treatment with SEV. However, increases in p-p38 and p-JNK expression levels were observed amongst cells that were pretreated with PAP. Furthermore, there were no significant differences in the expression levels of p38 and JNK in nerve cells treated with SEV and different concentrations of PAP (Fig. 6; P>0.05). To further investigate the role of the p38 pathway in mediating the effects of PAP, a p38 pathway inhibitor was employed. The extent of SEV-induced nerve cell injury was determined by detecting the expression levels of $\mathrm{Bcl}-2$ and $\mathrm{Bax}$ by western blotting. As presented in Fig. 7, in the presence of the $\mathrm{p} 38$ pathway inhibitor, the expression levels of Bcl-2 were decreased, whereas Bax expression levels were increased 

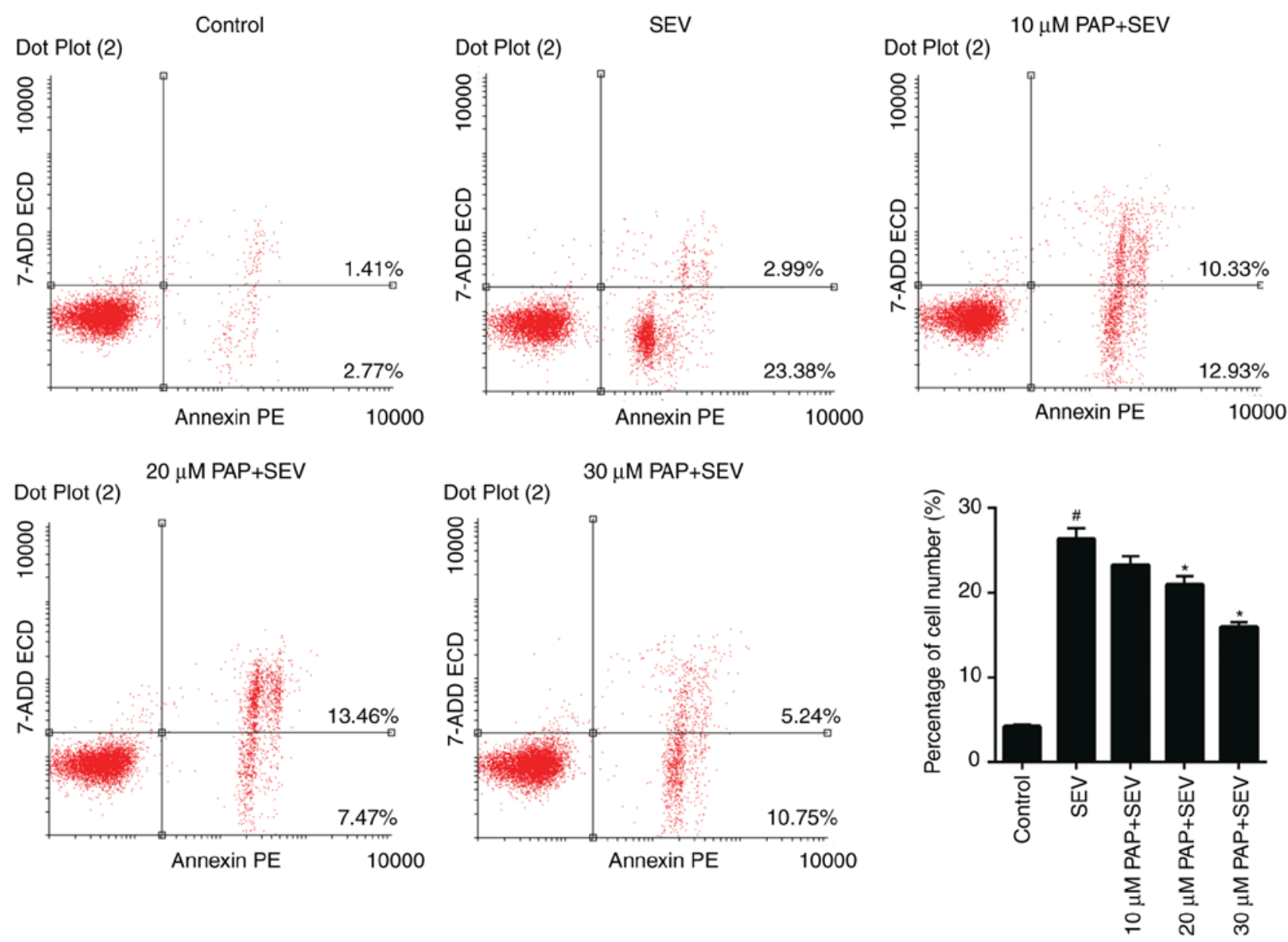

Figure 4. PAP suppresses the apoptosis of SEV-treated nerve cells. Flow cytometry was performed to assess apoptosis in nerve cells treated with SEV alone, or pretreated with different concentrations of PAP $(10,20$ and $30 \mu \mathrm{M})$ and then subjected to SEV. ${ }^{~} \mathrm{P}<0.05$ vs. Control. ${ }^{*}<0.05$ vs. SEV. 7-ADD, 7-aminoactinomycin D; PAP, pilose antler polypeptide; PE, phycoerythrin; SEV, sevoflurane.

compared with the SEV+PAP group. This suggested that the protective effects conferred by PAP were largely due to activation of the $\mathrm{p} 38 / \mathrm{JNK}$ pathway.

\section{Discussion}

The hippocampus is associated with learning, memory and other brain functions. It consists of a large number of neural stem cells. The hippocampal tissues of mammals, particularly fetal rats, may be easily obtained (27); thus, hippocampal neurons cultured in vitro are considered an ideal experimental model (28). PAP is the active substance in PA. Researchers have suggested that PAP may promote the proliferation of chondrocytes, and serves an important role in the development and progression of osteogenesis $(20,29)$. However, little is known about the protective effects of PAP in the central nervous system. Therefore, in the present study the potential protective effects of PAP in SEV-induced neurocyte injury were explored. When the concentration of PAP reached $40 \mu \mathrm{M}$, the cell viability of nerve cells began to decrease. In order to avoid cytotoxicity caused by PAP, cells were treated with 10, 20 and $30 \mu \mathrm{M}$ PAP for all subsequent experiments. The results also indicated that SEV significantly reduced the cell viability of nerve cells, while PAP markedly increased the cell viability of SEV-treated nerve cells. Therefore, the results demonstrated that PAP was able to enhance the cell viability of nerve cells during SEV-induced injury.
Since PAP enhanced the cell viability of nerve cells, it was suspected that PAP may affect the proliferation capacity of SEV-treated nerve cells. Thus, the proliferative ability of nerve cells treated with SEV and different concentrations of PAP was tested. The FCM data revealed that treatment with SEV significantly reduced the proliferation ability of nerve cells, while PAP increased the proliferation of SEV-treated nerve cells. These results indicated that PAP may have protective effects on nerve cells during SEV-induced injury. To further verify this, the apoptosis rates of nerve cells treated with SEV and different concentrations of PAP were determined. The results demonstrated that SEV promoted apoptosis in nerve cells, while PAP reduced apoptosis in SEV-treated nerve cells. Furthermore, the mechanisms underlying apoptosis in nerve cells treated with SEV and different concentrations of PAP were examined. In the present study, the expression levels of caspase-3, Bax and Bcl-2 in nerve cells were determined. The expression levels of caspase-3 and Bax were significantly upregulated by SEV in nerve cells; however, they were downregulated by PAP in SEV-treated nerve cells. Conversely, the expression levels of Bcl-2 were markedly downregulated by SEV and upregulated by PAP in nerve cells. These results suggested that PAP may suppress the apoptosis of SEV-treated nerve cells by modulating the expression levels of caspase-3, Bax and Bcl-2.

It has been previously demonstrated that the p38/JNK pathway is involved in processes associated with cell 


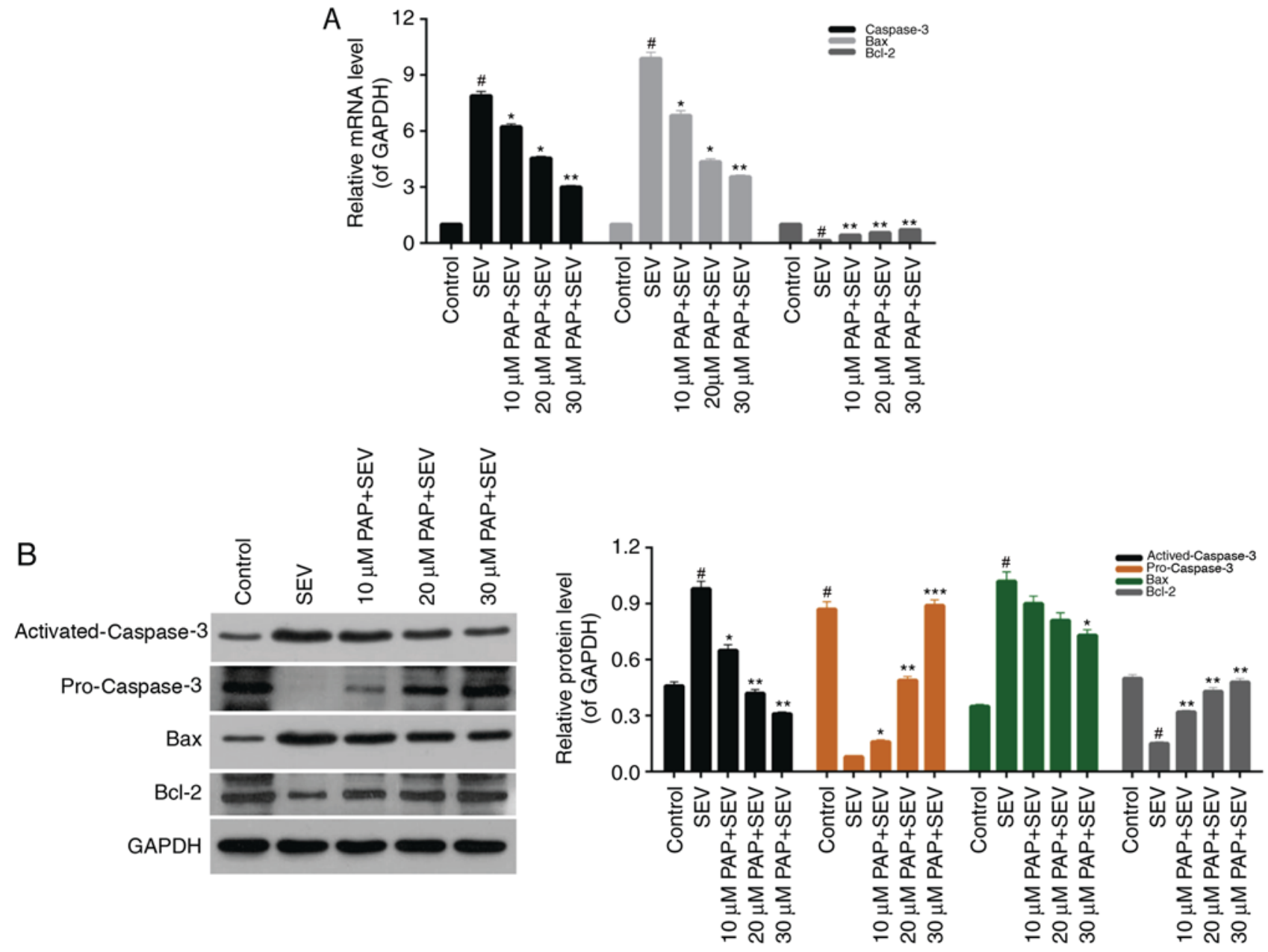

Figure 5. PAP modulates the expression of apoptosis-associated proteins. (A) Reverse transcription-quantitative polymerase chain reaction and (B) western blotting were performed to determine the mRNA and protein expression levels of caspase-3, Bax and Bcl-2 in nerve cells. Nerve cells were treated with SEV alone, or pretreated with different concentrations of PAP $(10,20$ and $30 \mu \mathrm{M})$ and subjected to SEV. ${ }^{\#} \mathrm{P}<0.05$ vs. Control. ${ }^{*} \mathrm{P}<0.05,{ }^{* *} \mathrm{P}<0.01,{ }^{* * * *} \mathrm{P}<0.001$ vs. respective SEV group. Bax, Bcl-2-associated X protein; Bcl-2, B-cell lymphoma 2; PAP, pilose antler polypeptide; SEV, sevoflurane.

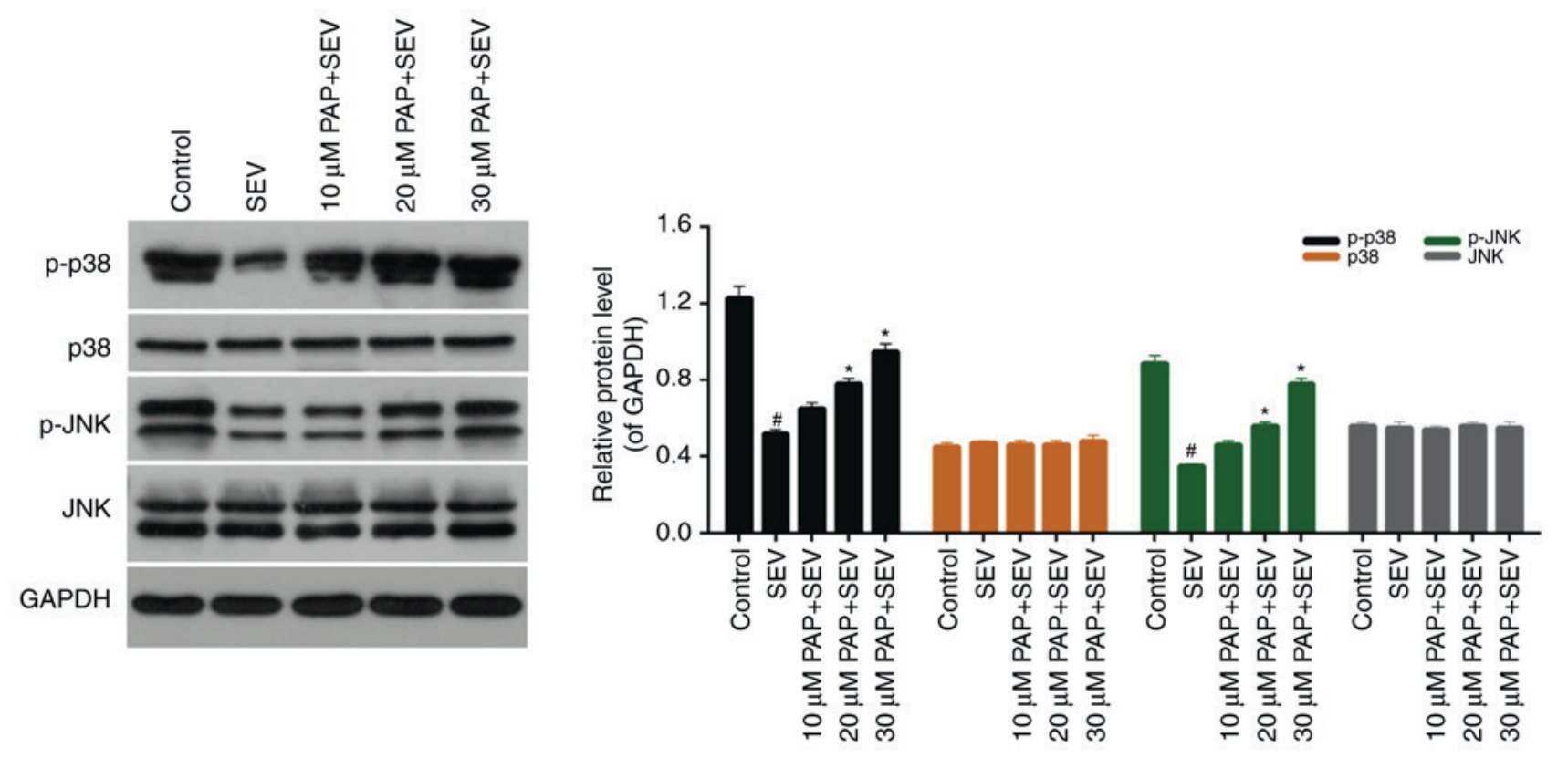

Figure 6. PAP activates the p38/JNK pathway. Western blot analysis was performed to evaluate the expression levels of p-p38, p38, p-JNK and JNK in nerve cells. Nerve cells were treated with SEV alone or pretreated with different concentrations of PAP $(10,20$ and $30 \mu \mathrm{M})$ and then subjected to SEV. ${ }^{\#} \mathrm{P}<0.05$ vs. Control. ${ }^{*} \mathrm{P}<0.05$ vs. respective SEV group. JNK, c-Jun N-terminal kinase; p, phosphorylated; p38, p38 mitogen-activated protein kinase; PAP, pilose antler polypeptide; SEV, sevoflurane. 

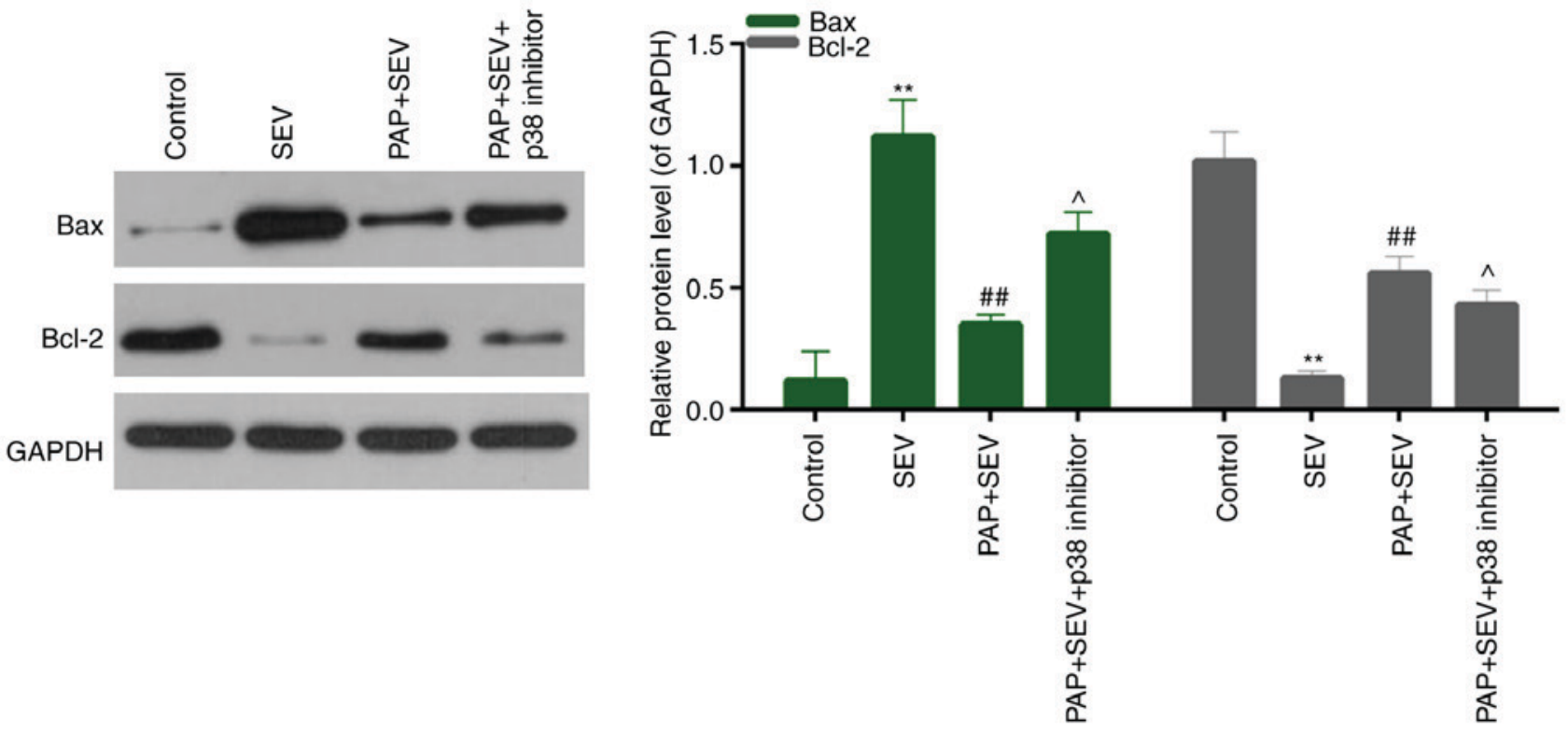

Figure 7. Inhibition of 38 blocks the protective effects of PAP. The expression levels of Bcl-2 and Bax were determined by western blotting. SB203580, a specific p38 inhibitor, was added to nerve cells and treated with $30 \mu \mathrm{M}$ PAP and subjected to SEV. ${ }^{* *} \mathrm{P}<0.01 \mathrm{vs.} \mathrm{Control;}{ }^{* \#} \mathrm{P}<0.01$ vs. SEV; ${ }^{\wedge} \mathrm{P}<0.05$ vs. PAP+SEV. Bax, Bcl-2-associated X protein; Bcl-2, B-cell lymphoma 2; p38, p38 mitogen-activated protein kinase; PAP, pilose antler polypeptide; SEV, sevoflurane.

proliferation and apoptosis in various types of cells (30-33). However, the effect of PAP on the p38/JNK pathway in nerve cells remains unclear. Therefore, the expression levels of $\mathrm{p}-\mathrm{p} 38$, p38, p-JNK and JNK in nerve cells were investigated. SEV markedly reduced the expression levels of p-p38 and p-JNK in nerve cells, while PAP increased the phosphorylation of p38 and JNK in SEV-treated nerve cells. According to these results, PAP modulated the p38/JNK pathway in SEV-treated nerve cells. Furthermore, inhibition of the p38/JNK pathway reversed the protective effects produced by PAP. The expression levels of Bcl-2 and Bax were decreased and increased, respectively, in the $\mathrm{p} 38$ inhibitor+SEV+PAP group compared with the SEV+PAP group. Therefore, activation of the p38 pathway may be necessary for mediating the protective effect of PAP.

In conclusion, the present study demonstrated that PAP protected against SEV-mediated neurocyte injury, which involved modulation of the $\mathrm{p} 38 / \mathrm{JNK}$ pathway. These findings provided novel insight on the pathogenesis of neurocyte injury and revealed a potential agent for treating neurocyte injury.

\section{Acknowledgements}

Not applicable.

\section{Funding}

No funding was received.

\section{Availability of data and materials}

The datasets used and/or analyzed during the current study are available from the corresponding author on reasonable request.

\section{Authors' contributions}

SL wrote the main manuscript. SL and JH performed the experiments. SL and JH designed the study. SL and JH performed data analysis. SL and JH contributed to manuscript revisions and both authors reviewed the manuscript.

\section{Ethics approval and consent to participate}

The protocols for the animal experiments were approved by the Ethics Committee of Xinjiang Uygur Autonomous Region Hospital of TCM.

\section{Patient consent for publication}

Not applicable.

\section{Competing interests}

The authors declare that they have no competing interests.

\section{References}

1. Cornelissen L, Kim SE, Purdon PL, Brown EN and Berde CB: Age-dependent electroencephalogram (EEG) patterns during sevoflurane general anesthesia in infants. Elife 4: e06513, 2015.

2. Dehaene-Lambertz G and Spelke ES: The infancy of the human brain. Neuron 88: 93-109, 2015.

3. Lee JH, Zhang J, Wei L and Yu SP: Neurodevelopmental implications of the general anesthesia in neonate and infants. Exp Neurol 272: 50-60, 2015.

4. Lerman J, Sikich N, Kleinman S and Yentis S: The pharmacology of sevoflurane in infants and children. Anesthesiology 80: 814-824, 1994.

5. Lee JR, Lin EP, Hofacer RD, Upton B, Lee SY, Ewing L, Joseph B and Loepke AW: Alternative technique or mitigating strategy for sevoflurane-induced neurodegeneration: A randomized controlled dose-escalation study of dexmedetomidine in neonatal rats. Br J Anaesth 119: 492-505, 2017. 
6. Bignami E, Biondi-Zoccai G, Landoni G, Fochi O, Testa V, Sheiban I, Giunta F and Zangrillo A: Volatile anesthetics reduce mortality in cardiac surgery. J Cardiothorac Vasc Anesth 23: 594-599, 2009

7. Lunardi N, Ori C, Erisir A and Jevtovic-Todorovic V: General anesthesia causes long-lasting disturbances in the ultrastructural properties of developing synapses in young rats. Neurotox Res 17: 179-188, 2010.

8. Tu S, Wang X, Yang F, Chen B, Wu S, He W, Yuan X, Zhang H, Chen $P$ and Wei G: Propofol induces neuronal apoptosis in infant rat brain under hypoxic conditions. Brain Res Bull 86: 29-35, 2011.

9. Briner A, De Roo M, Dayer A, Muller D, Habre W and Vutskits L: Volatile anesthetics rapidly increase dendritic spine density in the rat medial prefrontal cortex during synaptogenesis. Anesthesiology 112: 546-556, 2010.

10. Briner A, Nikonenko I, De Roo M, Dayer A, Muller D and Vutskits L: Developmental stage-dependent persistent impact of propofol anesthesia on dendritic spines in the rat medial prefrontal cortex. Anesthesiology 115: 282-293, 2011.

11. Wang Y, Cheng Y, Liu G, Tian X, Tu X and Wang J: Chronic exposure of gestation rat to sevoflurane impairs offspring brain development. Neurol Sci 33: 535-544, 2012.

12. Mintz CD, Barrett KM, Smith SC, Benson DL and Harrison NL: Anesthetics interfere with axon guidance in developing mouse neocortical neurons in vitro via a $\gamma$-aminobutyric acid type $\mathrm{A}$ receptor mechanism. Anesthesiology 118: 825-833, 2013.

13. Mintz CD, Smith SC, Barrett KM and Benson DL: Anesthetics interfere with the polarization of developing cortical neurons J Neurosurg Anesthesiol 24: 368-375, 2012.

14. Arbabi S and Maier RV: Mitogen-activated protein kinases. Crit Care Med 30 (1 Supp): S74-S79, 2002.

15. Ryu M, Kim EH, Chun M, Kang S, Shim B, Yu YB, Jeong G and Lee JS: Astragali Radix elicits anti-inflammation via activation of MKP-1, concomitant with attenuation of p38 and Erk. J Ethnopharmacol 115: 184-193, 2008.

16. Tang J, Chen X, Tu W, Guo Y, Zhao Z, Xue Q, Lin C, Xiao J, Sun $\mathrm{X}$, Tao T, et al: Propofol inhibits the activation of p38 through up-regulating the expression of annexin A1 to exert its anti-inflammation effect. PLoS One 6: e27890, 2011.

17. Barr RK and Bogoyevitch MA: The c-Jun N-terminal protein kinase family of mitogen-activated protein kinases (JNK MAPKs). Int J Biochem Cell Biol 33: 1047-1063, 2001.

18. Lin A: Activation of the JNK signaling pathway: Breaking the brake on apoptosis. Bioessays 25: 17-24, 2003.

19. Meng HY, Qu XB, Li N, Yuan S and Lin Z: Effects of pilose antler and antler glue on osteoporosis of ovariectomized rats. Zhong Yao Cai 32: 179-182, 2009 (In Chinese).

20. Liu G, Ma C, Wang P, Zhang P, Qu X, Liu S, Zhai Z, Yu D, Gao J, Liang J, et al: Pilose antler peptide potentiates osteoblast differentiation and inhibits osteoclastogenesis via manipulating the NF- $\kappa \mathrm{B}$ pathway. Biochem Biophys Res Commun 491 $388-395,2017$
21. Ma C, Long $\mathrm{H}$, Yang $\mathrm{C}$, Cai $\mathrm{W}$, Zhang $\mathrm{T}$ and Zhao $\mathrm{W}$ : Anti-inflammatory role of pilose antler peptide in LPS-induced lung injury. Inflammation 40: 904-912, 2017.

22. Chunhui Y, Wenjun C, Hui W, Liquan S, Changwei Z, Tianzhu Z and Wenhai Z: Pilose antler peptide protects osteoblasts from inflammatory and oxidative injury through EGF/EGFR signaling. Int J Biol Macromol 99: 15-20, 2017.

23. Suttie JM, Gluckman PD, Butler JH, Fennessy PF, Corson ID and Laas FJ: Insulin-like growth factor 1 (IGF-1) antler-stimulating hormone? Endocrinology 116: 846-848, 1985.

24. Wu T, Yang L, Chen Y, Ni Y, Jiang J, Zhang W, Zhou Q, Zheng X, Wang Q, Fu Z and Li H: Pilose antler polypeptides ameliorates hypoxic-ischemic encephalopathy by activated neurotrophic factors and SDF1/CXCR4 axis in rats. Acta Biochim Biophys Sin (Shanghai) 50: 254-262, 2018.

25. Zhou QL, Guo YJ, Wang LJ, Wang Y, Liu YQ, Wang Y and Wang BX: Velvet antler polypeptides promoted proliferation of chondrocytes and osteoblast precursors and fracture healing. Zhongguo Yao Li Xue Bao 20: 279-282, 1999.

26. Livak KJ and Schmittgen TD: Analysis of relative gene expression data using real-time quantitative PCR and the 2(-Delta Delta C(T)) method. Methods 25: 402-408, 2001.

27. Shitaka Y, Matsuki N, Saito H and Katsuki H: Basic fibroblast growth factor increases functional L-type Ca2+ channels in fetal rat hippocampal neurons: Implications for neurite morphogenesis in vitro. J Neurosci 16: 6476-6489, 1996.

28. Facci L and Skaper SD: Culture of rodent cortical and hippocampal neurons. Methods Mol Biol 846: 49-56, 2012.

29. Lin JH, Deng LX, Wu ZY, Chen L and Zhang L: Pilose antler polypeptides promote chondrocyte proliferation via the tyrosine kinase signaling pathway. J Occup Med Toxicol 6: 27, 2011.

30. Han Y, Wu G, Deng J, Tao J, Guo L, Tian X, Kang J, Zhang X and Yan C: Cellular repressor of E1A-stimulated genes inhibits human vascular smooth muscle cell apoptosis via blocking P38/JNK MAP kinase activation. J Mol Cell Cardiol 48: 1225-1235, 2010.

31. Hui L, Bakiri L, Mairhorfer A, Schweifer N, Haslinger C, Kenner L, Komnenovic V, Scheuch H, Beug H and Wagner EF: p38alpha suppresses normal and cancer cell proliferation by antagonizing the JNK-c-Jun pathway. Nat Genet 39: 741-749, 2007.

32. Kostadinova R, Montagner A, Gouranton E, Fleury S, Guillou H, Dombrowicz D, Desreumaux P and Wahli W: GW501516-activated PPAR $\beta / \delta$ promotes liver fibrosis via p38-JNK MAPK-induced hepatic stellate cell proliferation. Cell Biosci 2: 34, 2012.

33. Kuo WH, Chen JH, Lin HH, Chen BC, Hsu JD and Wang CJ: Induction of apoptosis in the lung tissue from rats exposed to cigarette smoke involves p38/JNK MAPK pathway. Chem Biol Interact 155: 31-42, 2005.

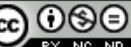

This work is licensed under a Creative Commons Attribution-NonCommercial-NoDerivatives 4.0 International (CC BY-NC-ND 4.0) License. 